\title{
Effect of Cutting Parameters in Machining Force, Surface Texture and Chips Morphology Obtained in Turning of Sintered Self-Lubricating Composites ${ }^{1}$
}

\author{
Felipe Gustavo Ebersbach ${ }^{a, b^{*}}$ (1), Sara Diaz Builes ${ }^{b}$, Caroline Francisco Dorneles ${ }^{b}$, \\ Rolf Bertrand Schroeter ${ }^{b}$,Cristiano Bindera, Aloísio Nelmo Klein ${ }^{a}$, José Daniel Biasoli de Mello ${ }^{a, c}$ \\ ${ }^{a}$ Universidade Federal de Santa Catarina (UFSC), Laboratório de Materiais (LabMat), \\ Departamento de Engenharia Mecânica, Florianópolis, SC, Brasil \\ ${ }^{b}$ Universidade Federal de Santa Catarina (UFSC), Laboratório de Mecânica de Precisão (LMP), \\ Departamento de Engenharia Mecânica, Florianópolis, SC, Brasil \\ 'Universidade Federal de Uberlândia (UFU), Laboratório de Tribologia e Materiais (LTM), \\ Faculdade de Engenharia Mecânica, Uberlândia, MG, Brasil
}

Received: March 26, 2020; Revised: June 21, 2020; Accepted: June 26, 2020

\begin{abstract}
This work presents a study on effect of cutting parameters in force, texture and chips morphology obtained during the turning of a self-lubricating sintered composite. The tests were performed varying the cutting speed $\left(\mathrm{v}_{\mathrm{c}}=100\right.$ and $\left.200 \mathrm{~m} / \mathrm{min}\right)$, feed $(\mathrm{f}=0.1$ and $0.2 \mathrm{~mm})$, depth of cut $\left(\mathrm{a}_{\mathrm{p}}=0.5\right.$ and $\left.1 \mathrm{~mm}\right)$, as well as the materials manufacturing route in single pressing (SP) and double pressing (DP). The variation in the cutting parameters influenced the components of the machining force. The cutting, feed and passive force were approximately $10 \%, 10 \%$ e $25 \%$ higher, respectively, for DP materials. The turning process generated surfaces with values of maximum height $\left(\mathrm{S}_{\mathrm{z}}\right)$ between 28.3 to $10.8 \mu \mathrm{m}$, Kurtosis $\left(\mathrm{S}_{\mathrm{ku}}\right)>3$ and Skewness $\left(\mathrm{S}_{\mathrm{ck}}\right)<0.3$. The chip type obtained was segmented and the chip thickness ratio was influenced by the variation of the cutting parameters and the materials manufacturing route.
\end{abstract}

Keywords: Turning, Machining force, Surface texture, Chips, Self-lubricating composites.

\section{Introduction}

Constant technological advances and the gradual increase in demands on the performance of materials are increasingly promoting the development of new materials with specific properties, for the most varied applications. Even with these advances, according to Binder et al. ${ }^{1}$, the performance of mechanical systems is impaired mainly by the deficiency of lubrication, which provides a great waste of mechanical energy. Approximately $20 \%$ of all energy consumed worldwide, according to Holmberg and Erdemir ${ }^{2}$, is used only to overcome friction. In vehicles that use fossil fuels, around $33 \%$ of the energy produced is wasted due to friction and wear ${ }^{3}$. Therefore, research aimed at improving the tribological performance of surfaces, particularly in reducing the friction coefficient, is becoming increasingly relevant. Mechanical systems that use materials with low friction coefficient provide a decrease in energy consumption and at the same time increase the durability of the parts involved in the system, which reduces the rate of disposal.

Self-lubricating composites, which incorporate solid lubricant particles in their volume, have a longer component life compared to coatings. After the wear of the coating, the contact between surfaces occurs increasing the wear rate, whereas when self-lubricating composite is worn, solid lubricants reservoir become available to form a lubricating

${ }^{1}$ This paper was presented in the 10th Brazilian Congress on Manufacturing Engineering, August 2019, São Carlos / SP.

"e-mail: felipe.ebersbach@gmail.com. film. Lubricant particles can be incorporated into the volume of the composite matrix when they are manufactured by the powder metallurgy process in the mixing step ${ }^{4-6}$, or generated by precipitation during the sintering process ${ }^{7,8}$.

Manufacture of materials via powder metallurgy provides porosities in its microstructure, which are influenced by several factors, such as the pressing pressure (in the case of materials manufactured by powder pressing), size and shape of the powder particles used, among others. However, powder metallurgy has the advantage of being able to produce parts with the finished geometry (near net shape). In cases where there is a need for a finishing process after sintering, according to Smith and Allsop ${ }^{9}$, machining can be used to adjust the dimensional and form tolerances, as well as to obtain the desired surface quality.

For the metal-mechanical industries, manufacturing processes have a fundamental importance both in technologic and economic areas. Walker ${ }^{10}$ comments that most of industrialized products present machining operations within their manufacturing stage. According to Trent and Wright ${ }^{11}$, the machining processes are responsible for transforming around $10 \%$ of all world metal production into chips and represent approximately $15 \%$ of the final value of products. As a result, among all manufacturing processes, the machining stands out due to its importance for manufacturing companies, stimulating the continuous development of new technologies and the constant study of machining processes. 
According to König and Klocke ${ }^{12}$ and Klocke ${ }^{13}$, the machinability of a material is usually evaluated for four criteria: tool life, machining force, chip formation and machined surface quality. These criteria are used to determine various factors, such as the wear of cutting tools, the dimensioning of machines, tools and fixing devices for parts, the development of geometries and materials for cutting tools, and the analysis of energy consumption, among others.

In machining, the low thermal conductivity caused by porosity (presents in sintered materials) results in the increase of temperature in the cutting region ${ }^{14}$. Moreover, according to M'saoubi et al. ${ }^{15}$, Nieslony and Kiszka ${ }^{16}$ and Grzesik $^{17}$, the porosity of sintered materials decreases the forces during machining, on the other hand, makes it difficult to obtain surfaces with good quality. The materials used in this research were developed by Hammes ${ }^{18}$. The development of these materials is quite recent, therefore, the knowledge related to their machining is practically nonexistent. In this context, this work presents a study on effect of cutting parameters $\left(v_{c}\right.$, f and $\left.a_{p}\right)$ in machining force components, texture of the machined surfaces and on the chips obtained during the external longitudinal turning of a self-lubricating composite. The composites were manufactured by single pressing - SP (700 MPa) and double pressing - DP (500 - $700 \mathrm{MPa})$, with $\mathrm{Fe}-4 \mathrm{Ni}-0.5 \mathrm{Si}$ matrix alloy mixed with solid lubricants $(6.5 \%$ vol of graphite and $1 \%$ vol of h-BN $)$ and sintered at $1125^{\circ} \mathrm{C}$.

\section{Materials and Methods}

The chemical composition of the self-lubricating composite studied is shown in Table 1. The materials were produced by mixing the pure iron powder AHC 100.29 (Höganäs Brasil Ltda) as a constituent of the matrix and silicon (Osprey Sandvik, Alloy Fe45Si, D50 = $10 \mu \mathrm{m}$ ) to harden the matrix and stabilize the alpha iron. The increase in the mechanical strength of the matrix was carried out with the addition of carbon (Höganäs, graphite UF4, D50 = $6 \mu \mathrm{m}$ ) and nickel (Inco, INCO $123, \mathrm{D} 50=3.9 \mu \mathrm{m})$. The solid lubricants used were hexagonal boron nitride (Momentive, AC6028, D50 = $125 \mu \mathrm{m}$ ) and coarse graphite (national graphite, Micrograph 99545HP, $\mathrm{D} 50=32 \mu \mathrm{m})$.

A type $\mathrm{Y}$ mixer was used to mix the powders for 45 minutes, with a rotation of $35 \mathrm{rpm}$. After mixing they are pressed in a hydraulic press with a double-action press. Two manufacturing routes were used to compact the materials: i) SP of $700 \mathrm{MPa}$ and ii) DP of 500 and $700 \mathrm{MPa}$. The materials, after pressing, were sintered in a hybrid plasma reactor ${ }^{19,20}$. In the two manufacturing routes (SP and DP), the final sintering was isothermal, at a temperature of $1125^{\circ} \mathrm{C}$ for $1 \mathrm{~h}$. The heating rate was $10^{\circ} \mathrm{C} / \mathrm{min}$ in an atmosphere of $95 \%$ argon and $5 \%$ hydrogen. The materials manufactured by double pressing were pre-sintered after compacting $500 \mathrm{MPa}$ for 30 minutes at a temperature of $700{ }^{\circ} \mathrm{C}$. After this stage, the materials were compacted at $700 \mathrm{MPa}$ and the final sintering was carried out. According to Hammes et al. ${ }^{5}$, double pressing increases the density of composites in relation to single pressing, which results in an increase in the mechanical properties of the material. The geometry of the samples is cylindrical, with a diameter and height of $30 \mathrm{~mm}$.
The micrograph of the SP material is shown in Figure 1, obtained by the Olympus optical microscope, model BX60M. Note that the material has a microstructure with a large amount of ferrite with coarse perlite, fine perlite, pores (from powder metallurgy) and/or solid lubricant reservoirs. The materials manufactured by double pressing had a microstructure similar to that shown in Figure 1.

The average hardness of the SP and DP materials, for 6 measurements, was 145 and $170 \mathrm{HB}$, respectively. Tensile tests were performed on composites, according to MPIF ${ }^{21}$, on an MTS 810 universal testing machine. The SP materials have maximum tensile stress and yield stress (Figure 2) of $205 \mathrm{MPa}$ and $197 \mathrm{MPa}$, respectively. DP materials had a maximum tensile strength of $402 \mathrm{MPa}$ and yield stress of $267 \mathrm{MPa}$ (Figure 2). This increase in the mechanical properties of DP material in relation to SP material is due to the reduction in the porosity of materials, which is around $25 \%$, according to Hammes et al. ${ }^{5}$.

\subsection{Experimental techniques}

The machining tests were carried out in a Heyligenstaedt CNC lathe, model Heynumat 10, with spindle drive power of $70 \mathrm{~kW}$ and maximum rotation of $4500 \mathrm{rpm}$. The materials

Table 1. Chemical composition of the material.

\begin{tabular}{|c|c|c|c|c|c|c|}
\hline & $\mathrm{Fe}$ & $\begin{array}{l}\text { h-BN } \\
\left(\%{ }_{\text {vol }}\right)\end{array}$ & $\begin{array}{c}\mathrm{Ni} \\
\left(\%{ }_{\mathrm{wt}}\right) \\
\end{array}$ & $\begin{array}{c}\mathrm{C} \\
\left(\%_{\mathrm{wt}}\right)\end{array}$ & $\begin{array}{c}\text { C coarse } \\
\left(\%_{\text {vol }}\right)\end{array}$ & $\begin{array}{c}\mathrm{Si} \\
\left(\% \%_{w t}\right)\end{array}$ \\
\hline Alloy & Balance & 1 & 4 & 0.8 & 6.5 & 0.5 \\
\hline
\end{tabular}

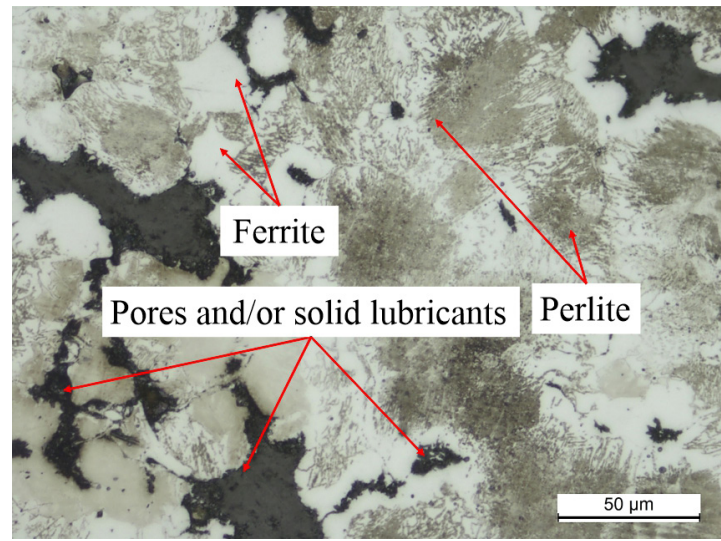

Figure 1. Microstructure of the SP composite.

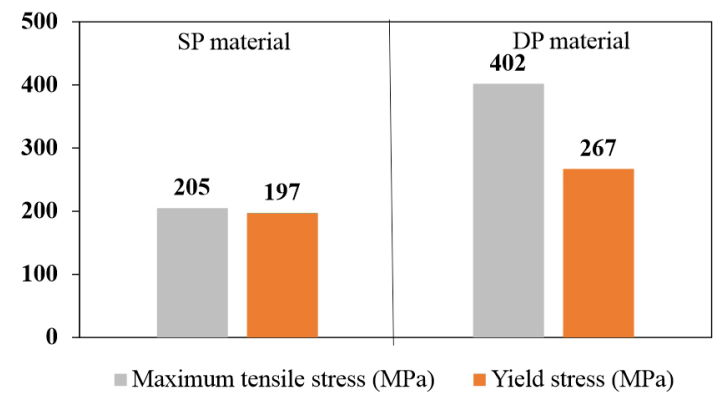

Figure 2. Maximum tensile stress and yield stress for the SP and DP materials. 
were machined by longitudinal external turning using wiper carbide inserts (P20 grade), ISO code TCMX 16T308-WF 1515, with $\mathrm{Ti}(\mathrm{C}, \mathrm{N})+\mathrm{AL}_{2} \mathrm{O}_{3}+\mathrm{TiN}$ coating, $0.8 \mathrm{~mm}$ corner radius, side relief angle of $7^{\circ}$ and side rake angle of $13^{\circ}$, manufactured by Sandvik. The inserts were fixed on a support (ISO code STGCL 2020K 16) with an approach angle of $91^{\circ}$, back rake angle and side rake angle of $0^{\circ}$.

The machining tests were carried out dry, varying the cutting parameters, cutting speed $\left(\mathrm{v}_{\mathrm{c}}=100\right.$ and $\left.200 \mathrm{~m} / \mathrm{min}\right)$, feed $(0.1$ and $0.2 \mathrm{~mm})$ and depth of cut $\left(\mathrm{a}_{\mathrm{p}}=0.5\right.$ and $\left.1 \mathrm{~mm}\right)$ and the materials manufacturing route (SP and DP). Using these parameters, a DOE with 16 tests was developed (Table 2). Each machining test presented 2 replicates, totaling 32 tests performed.

The measurement of the cutting force, feed force and passive force during the tests was performed using a piezoelectric platform, manufactured by the company Kistler Instrument AG, model $9257 \mathrm{~A}$, with the aid of amplifiers, also from Kistler, model 5011 and 5006, connected to a National Instruments acquisition board, model NI USB 6218. The verification of the operation of the force measurement system was carried out in the research developed by Ebersbach $^{22}$ and Ebersbach et al. ${ }^{23}$. The values of machining force components were determined by the difference between the signals average obtained during the cutting and the signals average obtained during the non-cutting (Figure 3). As a consequence of this, the measurement of forces with relative values was adopted. An acquisition rate of $10 \mathrm{kHz}$ was used for the 3 components of the machining force (cutting force, feed force and passive force).

The texture of the machined surfaces was measured in 4 regions, each area measuring $4 \mathrm{~mm}^{2}$, using the roughness parameter $\mathrm{S}_{\mathrm{z}}$ (maximum height) and the surface morphological space (parameter $\mathrm{S}_{\mathrm{ku}}$ - Kurtosis and parameter $\mathrm{S}_{\text {sk }}$ - Skewness). For this, it was used a Zygo white light interferometer, model Newview 7300 , with lateral resolution of $0.28 \mu \mathrm{m} /$ point and vertical resolution of $0.1 \mathrm{~nm}$.

The processing of the measured values of the evaluated roughness parameters was made with the aid of the MountainsMap 7.0 software. The quantification of the roughness parameters occurred after the removal of the cylindrical shape and the correction of the undulation by means of a $250 \mu \mathrm{m}$ Robust Gaussian filter, according to the ISO $16610-71^{24}$. The machined surfaces were compared to the surfaces after the sintering process.

After each machining test, chips were collected. The type and chips shape were evaluated using a Hitachi Scanning Electron Microscope (SEM), model TM-3030. The chip thickness ratio $(\Omega)$ was calculated by dividing the chip thickness (h') by the undeformed chip thickness (h), according to Equation 1. For this, the chips were embedded with hot resin and made metallographic tests. Images of the embedded chips were obtained using an Olympus optical microscope, model BX60M, where measurements (10 measurements) of the chip thickness were made. All data obtained were evaluated using analysis of variance (ANOVA) with a significance level of 0.05 according to Montgomery and Runger ${ }^{25}$.

$\boldsymbol{\Omega}=\frac{\mathrm{h}^{\prime}}{\mathrm{h}}$

\section{Results and Discussion}

\subsection{Machining force}

The mean values of the cutting force, feed force and passive force, with their respective confidence intervals, for both the SP and DP material, are shown in Figure 4.

It can be seen that regardless of the materials manufacturing route, for both the depths of cut and feed tested, the increase in the cutting speed resulted in a reduction in the values of the cutting force (Figure $4 a-b)$. The increase in the cutting speed from 100 to $200 \mathrm{~m} / \mathrm{min}$ led to a decrease in cutting force of around $10 \%$ and $8 \%$ for materials SP (Figure $4 \mathrm{a}$ ) and DP (Figure 4b), respectively

The same behavior was observed for the feed and passive forces (Figure 4c-e). The increase in cutting speed resulted in a reduction of the feed force by approximately $18 \%$ for SP materials and $15 \%$ for DP materials. The reduction of the passive force with the increase of the cutting speed was of approximately 25\%, for both materials (SP and DP). The increase in the cutting speed results in an increase in the temperature in the cutting region, thus causing a reduction in the components of the machining force due to the loss of the mechanical strength of the materials when subjected to higher temperatures ${ }^{11-15,26}$. The variation in the cutting speed had a significant influence on the cutting force $(\mathrm{P}$-value $=0.001)$, feed force $(\mathrm{P}$-value $=0.011)$ and passive force $(\mathrm{P}$-value $=0.000)$.

Table 2. Tests conducted with their respective cutting parameters.

\begin{tabular}{ccccc}
\hline Tests & $\mathrm{v}_{\mathrm{c}}(\mathrm{m} / \mathrm{min})$ & $\mathrm{f}(\mathrm{mm})$ & $\mathrm{a}_{\mathrm{p}}(\mathrm{mm})$ & $\begin{array}{c}\text { Manufacturing } \\
\text { route }\end{array}$ \\
\hline 1 & 200 & 0.2 & 1.0 & \\
\cline { 1 - 4 } & 200 & 0.2 & 0.5 & $\mathrm{SP}$ \\
\hline 3 & 200 & 0.1 & 1.0 & \\
\hline 4 & 200 & 0.1 & 0.5 & \\
\hline 5 & 200 & 0.2 & 1.0 & \\
\hline 6 & 200 & 0.2 & 0.5 & $\mathrm{DP}$ \\
\hline 7 & 200 & 0.1 & 1.0 & \\
\hline 8 & 200 & 0.1 & 0.5 & \\
\hline 9 & 100 & 0.2 & 1.0 & \\
\hline 10 & 100 & 0.2 & 0.5 & $\mathrm{SP}$ \\
\hline 11 & 100 & 0.1 & 1.0 & \\
\hline 12 & 100 & 0.1 & 0.5 & \\
\hline 13 & 100 & 0.2 & 1.0 & \\
\hline 14 & 100 & 0.2 & 0.5 & $\mathrm{DP}$ \\
\hline 15 & 100 & 0.1 & 1.0 & \\
\hline 16 & 100 & 0.1 & 0.5 & \\
\hline
\end{tabular}

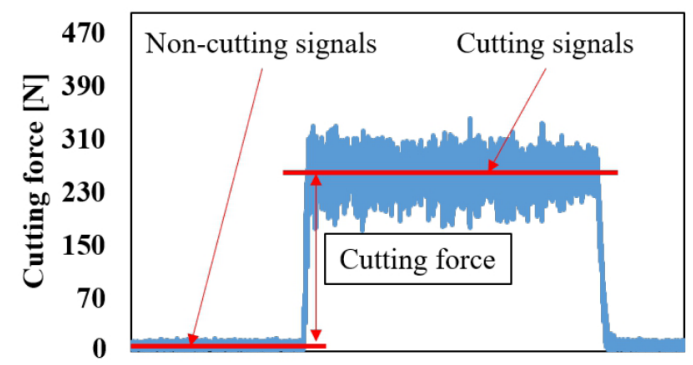

Time (s)

Figure 3. Measurement of forces with relative values. 


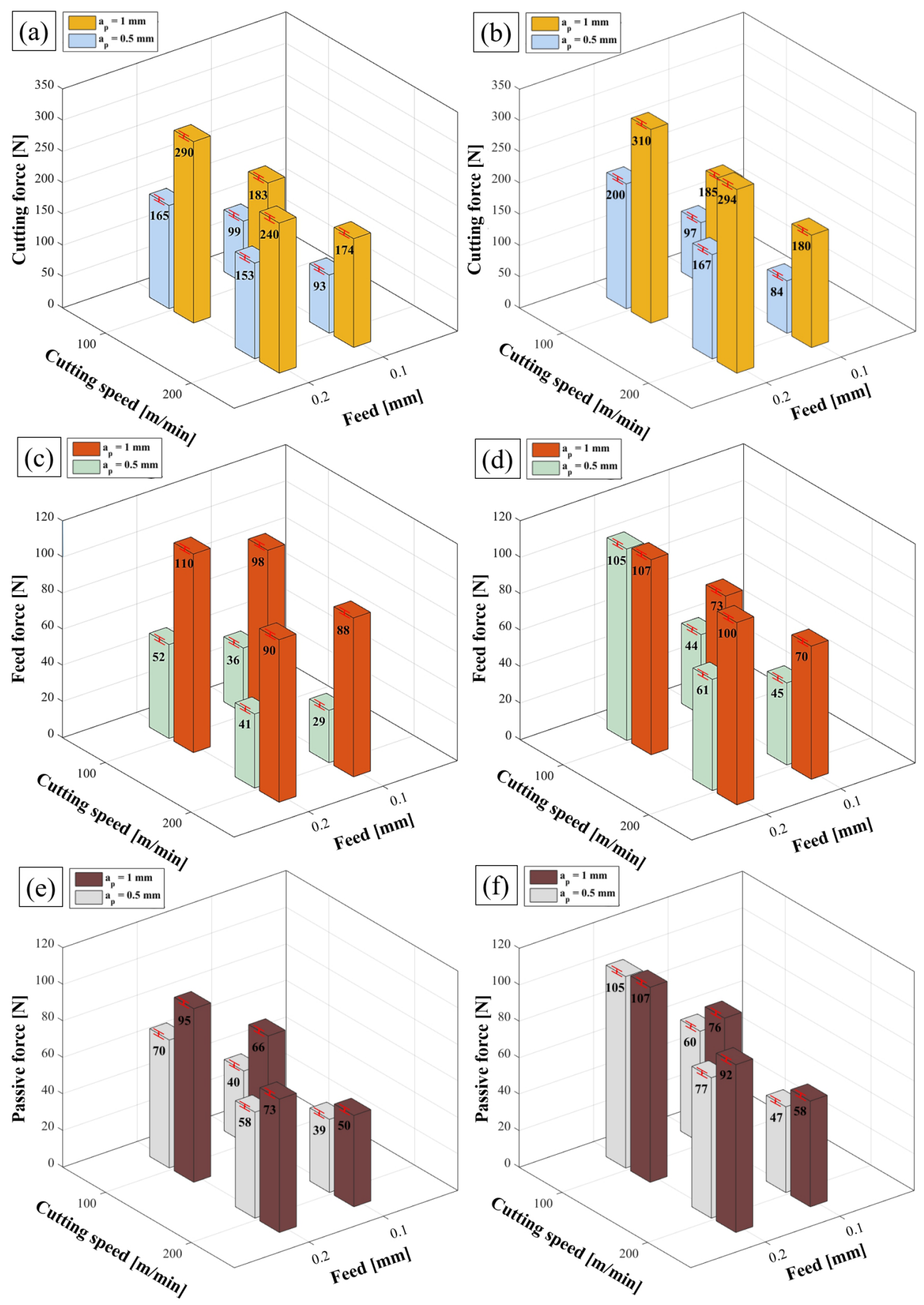

Figure 4. Average values of cutting force, feed force and passive force in function of cutting speed, feed, and depth of cut for SP (a, c and e) and DP materials (b, $d$ and $f)$. 
For both SP and DP materials, the feed variation resulted in an increase in the cutting force (Figure $4 a$ and $2 b$ ), regardless of the variation in cutting speed and depth of cut. The increase of the feed from 0.1 to $0.2 \mathrm{~mm}$, led to an increase in the values obtained of the cutting force around $55 \%$ and $80 \%$ for the materials SP and DP, respectively.

The behavior for the feed and passive forces was similar with the feed variation (Figure 4c-e). The increase in feed led to an increase in the values obtained for the feed force around $25 \%$, for SP materials, and $60 \%$, for DP materials. The passive force increased by approximately $50 \%$ for SP materials and $60 \%$ for DP materials, with an increase in feed from 0.1 to $0.2 \mathrm{~mm}$. The increase in the cutting thickness occurs with the increase of the feed, causing in a greater amount of material removed, resulting in an increase in the machining force components ${ }^{11-14,27,28}$. Through ANOVA, the variation of the feed had a significant influence on the cutting force $(\mathrm{P}$-value $=0.000)$, the feed force $(\mathrm{P}$-value $=0.000)$ and passive force $(\mathrm{P}$-value $=0.000)$.

The increase in depth of cut from 0.5 to $1 \mathrm{~mm}$ led to an increase in cutting force of around $75 \%$ and $95 \%$ for SP and DP materials (Figure $4 \mathrm{a}$ and $3 \mathrm{~b}$ ), respectively. The feed force showed an increase of approximately $100 \%$ for SP materials and 50\% for DP materials (Figure $4 \mathrm{c}$ and 3d). The increase in passive force was around $40 \%$ and $20 \%$ for SP and DP materials, respectively (Figure $4 \mathrm{e}$ and $3 \mathrm{f}$ ), with increases in depth of cut.

According to Trent and Wright ${ }^{11}$, König and Klocke ${ }^{12}$ and Klocke ${ }^{13}$ the increase in depth of cut causes an increase in the cutting width, which results in an increase in the machining force components. Based on the Kienzle equations for cutting, feed and passive forces, increasing the cutting width theoretically results in a proportional increase in the machining force components. However, with the increase in the depth of cut from 0.5 to $1 \mathrm{~mm}$, there was no proportional increase in the cutting force, feed force and passive force (Figure 4). According to Yallese et al. ${ }^{26}$, the disproportionate increase in the machining force components may occur, for example, due to plastic deformations and the thermal conductivity of the machined material, as well as by vibrations from the machining process. However, as the materials studied in the present research have heterogenic structure, due to the pores from the powder metallurgy process and the solid lubricants reservoirs (Figure 1), this may have influenced the disproportionate increase in the machining force components with increasing depth of cut.

In tests performed with depth of cut of $0.5 \mathrm{~mm}$, the values obtained for the passive force were higher than the values of the feed force (Figure $4 \mathrm{c}-\mathrm{e}$ ), around $30 \%$ and $20 \%$ for SP materials and DP, respectively. According to Pramanik et al. ${ }^{29}$, in conditions in which the depth of cut $\left(a_{p}\right)$ is less than the tool's corner radius $\left(\mathrm{r}_{\varepsilon}\right)$, the angle of direction of the equivalent edge is reduced, which causes a reduction in the average chip thickness. Thus, the machined surfaces, in the condition in which the $a_{p}<r_{\varepsilon}$, tend to show increases in the rate of plastic deformations and in specific forces due to the decrease in the average chip thickness ${ }^{12,13,29}$. The variation in the depth of cut had a significant influence on the cutting force $(\mathrm{P}$-value $=0.000)$, feed force $(\mathrm{P}$-value $=0.000)$ and passive force $(\mathrm{P}$-value $=0.000)$.
The increase in mechanical strength, approximately $50 \%$, of DP materials compared to SP materials (Figure 2), resulted in an increase in cutting force, feed force and passive force (Figure 4 ), around $10 \%, 10 \%$ and $25 \%$, respectively. The increase in the mechanical strength of a material leads to an increase in the machining force components, due to the greater resistance that the material to be machined presents for cutting tool penetrates and form the chips ${ }^{11-13}$. Through ANOVA, the materials manufacturing route had significant influence only in the cutting force $(\mathrm{P}$-value $=0.006)$ and in the passive force $(\mathrm{P}$-value $=0.000)$.

\subsection{Quality of the machined surface}

Figure 5 shows the average values of $\mathrm{S}_{\mathrm{z}}$ with their respective confidence intervals, with the variation of the cutting parameters for the materials SP and DP. The values obtained for $\mathrm{S}_{\mathrm{z}}$ in the SP materials (Figure 5a), were between 28.3 and $11.3 \mu \mathrm{m}$. For the materials manufactured with DP the measured values of $\mathrm{S}_{\mathrm{z}}$ (Figure $5 \mathrm{~b}$ ) remained between 19.9 and $10.8 \mu \mathrm{m}$.

Regardless of the manufacturing route and the variation in the depth of cut and feed it was verified that the increase in the cutting speed resulted in a reduction in $\mathrm{S}_{\mathrm{z}}$ values. The increase in the cutting speed from 100 to $200 \mathrm{~m} / \mathrm{min}$ led to a decrease in $\mathrm{S}_{\mathrm{z}}$ values around $60 \%$ and $65 \%$ for SP materials (Figure $5 \mathrm{a}$ ), and approximately $65 \%$ for DP materials (Figure $5 \mathrm{~b}$ ).

The temperature in the cutting region is directly proportional to the cutting speed. Materials subjected to higher temperatures lose mechanical strength. Therefore, the
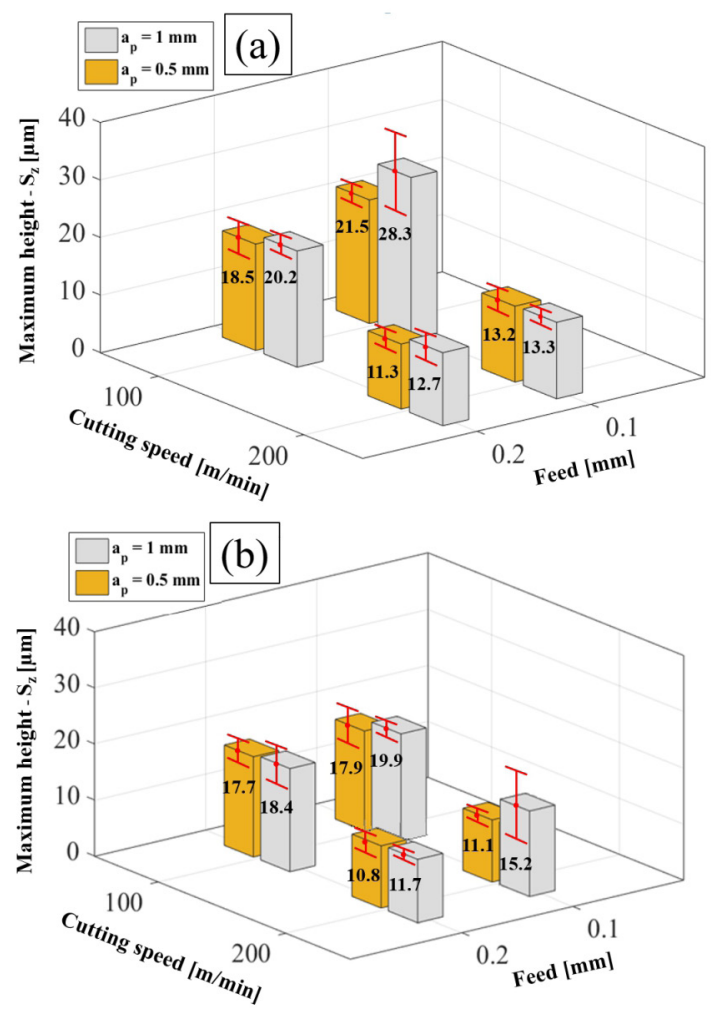

Figure 5. Average values with a confidence interval of the maximum height $-\mathrm{S}_{z}$ as a function of the cutting parameters for the machined surface of (a) SP and (b) DP material. 
increase in cutting speed facilitates the removal of material by the cutting tool, consequently reducing the machining force components ${ }^{11-15,26,30-33}$, according to the results found in the present research (Figure 4). Rao and Allamraju ${ }^{27}$, Neugebauer et al. ${ }^{33}$ and Manivel and Gandhinathan ${ }^{34}$ comment that one of the factors of great importance in the providing of machined surface textures is the thermal softening provided by the increase in temperature in the cutting region. Salak et al. ${ }^{14}$ commented that sintered materials, due to the discontinuity of the material matrix, have low thermal conductivity, which results in a higher temperature increase in the cutting region. Hence, the increase of the cutting speed leads to the reduction of the machining force components, due to the increase of the cutting temperature, providing machined surfaces with lower values of $\mathrm{S}_{\mathrm{z}}$. The variation in cutting speed had a significant influence $(\mathrm{P}$-value $=0.004)$ on $\mathrm{S}_{\mathrm{z}}$.

Through ANOVA it was demonstrated that the variation of the feed did not present significant influence in the values obtained for $\mathrm{S}_{\mathrm{z}}(\mathrm{P}$-value $=0.810)$, for both materials manufacturing routes. However, it is noticeable that the increase in the feed, regardless of the manufacturing route of the materials and varied cutting parameters, presented a tendency to reduce the maximum height $-\mathrm{S}_{\mathrm{z}}$ (Figure 5).

The components of the machining force increase with increasing feed (Figure 4). According to Rao and Allamraju ${ }^{27}$, the increase in the feed provides a higher rate of plastic deformation and friction, resulting in an increase in temperature. The nose geometry of the inserts used in the machining of the surfaces of this study is wiper type, also known as a straightening tool. This type of geometry aims to reduce the values of the roughness parameters by increasing the contact area with the machined surface. The increased friction with the machined surface results in an increase in temperature ${ }^{31,32,35}$. Therefore, the increase in temperature caused by the increase in feed, as well as the increase in the area of contact with the machined surfaces, was possibly responsible for the observed behavior of $\mathrm{S}_{\mathrm{z}}$ (Figure 5).

The variation in the depth of cut did not show any significant influence $(\mathrm{P}$-value $=0.789)$ on the values obtained for $\mathrm{S}_{\mathrm{z}}$ (Figure 5). Possibly, the significant non-influence with variation of feed and depth of cut was due to the type of inserts used in the tests (wiper). The increase in the contact area of the tool with the machined surface of this type of insert $^{31,32,36}$, generates an increase in the plastic deformation on the surface, hiding the marks left by the cutting tool ${ }^{37}$, and consequently, interfering in the topography of machined surfaces.

Through ANOVA, the manufacturing route of the materials (SP and DP) did not show significant influence on the values obtained for $\mathrm{S}_{\mathrm{z}}(\mathrm{P}$-value $=0.587)$. However, it was identified that there is a tendency to reduce the values obtained for $\mathrm{S}_{\mathrm{z}}$ of the SP materials for the DP materials by around $15 \%$ (Figure 5). DP materials have an increase of around 50\% in mechanical strength compared to SP materials (Figure 2). The increase in the mechanical strength of a material provides the formation of smaller burrs in the machined parts and tends to improve the surface finish due to the lower ductility of the material and the higher temperature reached in the cutting region ${ }^{11-13,27}$. This increase in the mechanical strength of the double pressing materials is due to the reduction of the pore size from powder metallurgy. Hence, it is easier to close them through the plastic deformation imposed by machining. Therefore, with a greater amount of closed pores in the machined surface, a smaller variation of the surface texture is obtained, resulting in lower $\mathrm{S}_{\mathrm{z}}$.

Figure 6 shows the average values of $\mathrm{S}_{\mathrm{ku}}$ vs $\mathrm{S}_{\text {sk }}$ (morphological space) of the machined surfaces. Regardless of the materials manufacturing route is observed that the surfaces machined with $\mathrm{v}_{\mathrm{c}}=100 \mathrm{~m} / \mathrm{min}$ (Figure $6 \mathrm{~b}$ ), present a roughness with a less accentuated height distribution $\left(\mathrm{S}_{\mathrm{ku}}<5\right)$ associated with a lower valley distribution $\left(\mathrm{S}_{\mathrm{sk}}>-0.2\right)$ in relation to the machined surfaces with $\mathrm{v}_{\mathrm{c}}=200 \mathrm{~m} / \mathrm{min}$ (Figure 6a).

With a lower cutting speed, the forces acting during the machining process are greater (Figure 4 ). As a result, associated with a ferritic microstructure of the materials (Figure 1), which presents high deformability ${ }^{11-13}$, greater plastic deformations were induced in the machined surfaces, generating surfaces with less distribution of valleys (parameter $\mathrm{S}_{\mathrm{sk}}$ ) and height distribution (parameter $\mathrm{S}_{\mathrm{ku}}$ ). Through ANOVA, the variation of the cutting speed had significant influence $(\mathrm{P}$-value $=0.003)$ in the morphological space of the machined surfaces. Therefore, the cutting speed of $200 \mathrm{~m} / \mathrm{min}$ generated surfaces with lower $\mathrm{S}_{\mathrm{z}}$ values (Figure 5), with a more pronounced height distribution $\left(\mathrm{S}_{\mathrm{ku}}\right.$ - Figure 6$)$ and a greater distribution of valleys $\left(\mathrm{S}_{\mathrm{sk}}\right.$ - Figure 6).
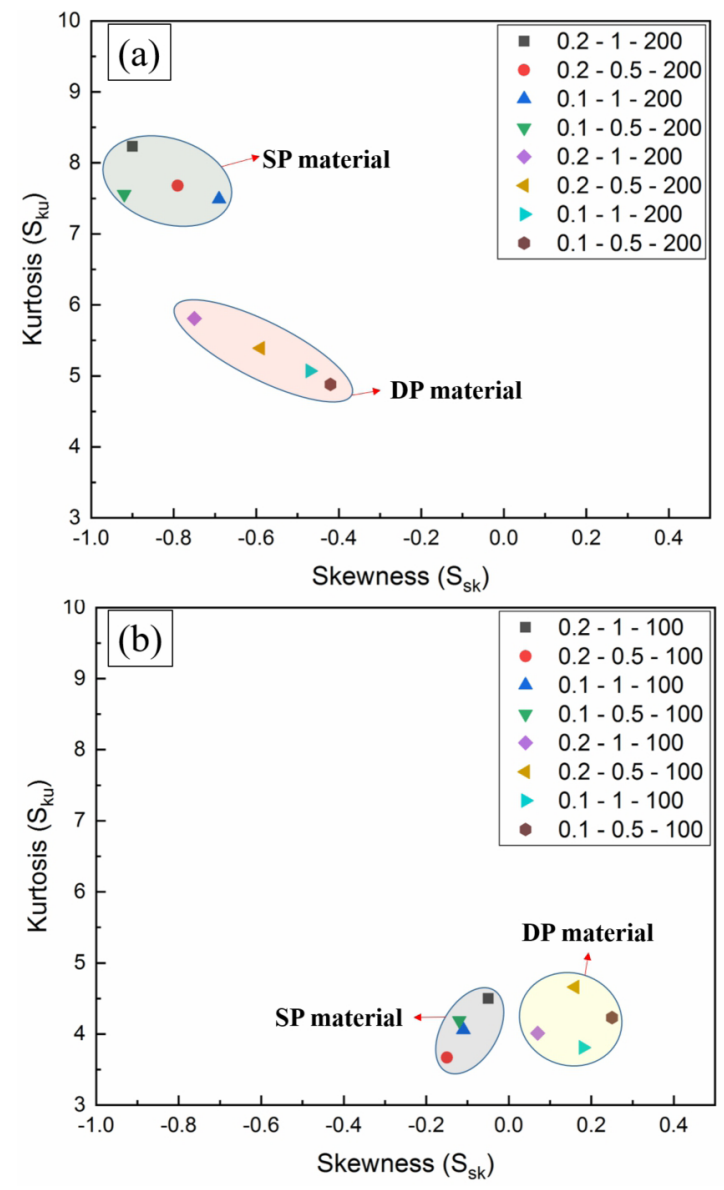

Figure 6. Morphological space of machined surfaces with (a) $\mathrm{v}_{\mathrm{c}}=200 \mathrm{~m} / \mathrm{min} \mathrm{e} \mathrm{(b)} \mathrm{v}_{\mathrm{c}}=100 \mathrm{~m} / \mathrm{min}$. 
Regardless of the variation in the cutting speed, the variation in feed and depth of cut did not have a significant influence $(\mathrm{P}$-value $=0.675)$ on the morphological space of the machined surfaces.

It can be observed that, for the surfaces machined with $\mathrm{v}_{\mathrm{c}}=200 \mathrm{~m} / \mathrm{min}$ (Figure 6a), the SP materials presented surfaces with a more pronounced height distribution $\left(\mathrm{S}_{\mathrm{ku}}>7\right)$ consequently with a greater distribution of valleys $\left(\mathrm{S}_{\mathrm{sk}}<-0.6\right)$ when compared to surfaces machined in DP materials. On the surfaces machined with $\mathrm{v}_{\mathrm{c}}=100 \mathrm{~m} / \mathrm{min}$ (Figure 6b), it is noted that the surfaces machined in SP materials present a greater distribution of valleys $\left(\mathrm{S}_{\mathrm{sk}}<0\right)$. DP materials showed greater forces during machining compared to SP materials (Figure 4). Due to greater plastic deformations on the machined surfaces lower $\mathrm{S}_{\mathrm{ku}}$ and $\mathrm{S}_{\mathrm{sk}}$ parameters were generated. Through ANOVA, the materials manufacturing
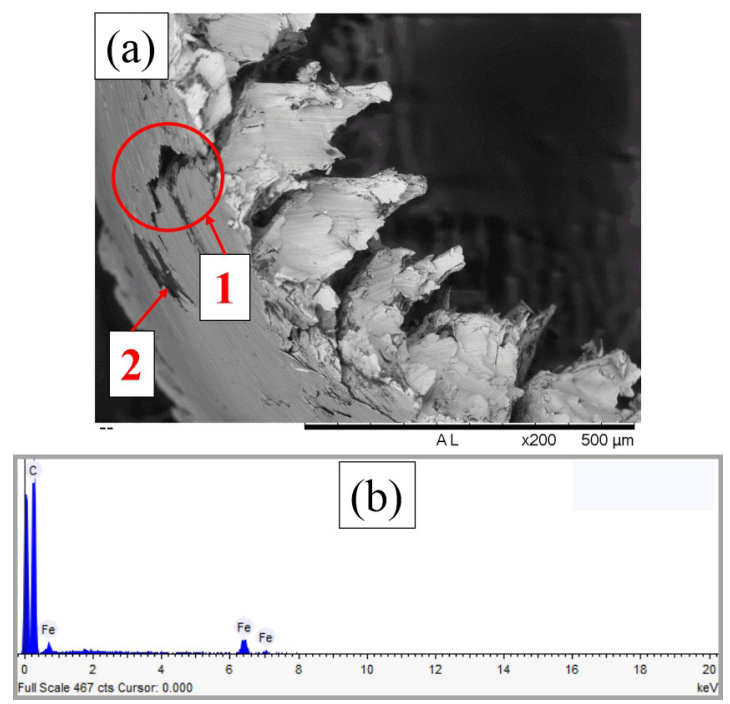

Figure 7. (a) Morphology of the chip formed with $\mathrm{v}_{\mathrm{c}}=200 \mathrm{~m} / \mathrm{min}$, $\mathrm{f}=0.2 \mathrm{~mm} \mathrm{e}_{\mathrm{p}}=1 \mathrm{~mm}$ in SP material and (b) EDX spectroscopy in point 2 . route had a significant influence (P-value- 0.003 ) only in the values obtained from $\mathrm{S}_{\mathrm{sk}}$. The machining of surfaces in DP materials generated lower $\mathrm{S}_{\mathrm{z}}$ values (Figure 5), with a lower distribution of valleys $\left(\mathrm{S}_{\mathrm{sk}}\right.$ - Figure 6$)$.

\subsection{Chips analysis}

The chip morphology obtained with $\mathrm{v}_{c}=200 \mathrm{~m} / \mathrm{min}$, $\mathrm{f}=0.2 \mathrm{~mm}$ and $\mathrm{a}_{\mathrm{p}}=1 \mathrm{~mm}$ in the SP material is shown in Figure 7a. It is noticeable that the periodic formation of segments occurs, which classifies the chip as segmented ${ }^{12,13}$. According to $\mathrm{Klocke}^{13}$, this periodicity can be caused due to vibrations that can lead to variations in the chip thickness, as well as the heterogenic structure of the material. At the bottom of the chip (identified by " 1 " in Figure 7a), the crack propagation can be seen, which could have been caused by the presence of pores (from the powder metallurgy process) and/or solid lubricant reservoirs. The porosity of materials manufactured by powder metallurgy provides a reduction in the thermal conductivity of the material, resulting in higher temperatures reached in the cut region during machining ${ }^{14}$. Thus, according to Komanduri and Brown ${ }^{38}$, the formation of periodic events can occur in materials with poor heat transfer, which can lead to the formation of segmented chips.

In the point identified by 2 (Figure 7), the presence of solid lubricants at the bottom of the chip was confirmed by EDX spectroscopy (Figure 7b). In this case, the solid lubricant presents in the volume of materials helps to reduce the coefficient of friction at the chip-tool interface, thus providing lower forces acting during the machining process. Regardless of the variation of the cutting parameters and material manufacturing route, all the chips obtained have the same characteristics of those shown in Figure 7.

The influence of the feed rate, the depth of cut and the materials manufacturing route in the chips shape, obtained with $\mathrm{v}_{\mathrm{c}}=200 \mathrm{~m} / \mathrm{min}$, is shown in Figure 8 . It was identified that regardless of the variation of the cutting parameters and the manufacturing route, the chips have an arc shape. The variation of the feed from 0.1 to $0.2 \mathrm{~mm}$, both for the SP material (Figure 8a) and for the DP material (Figure 8b),

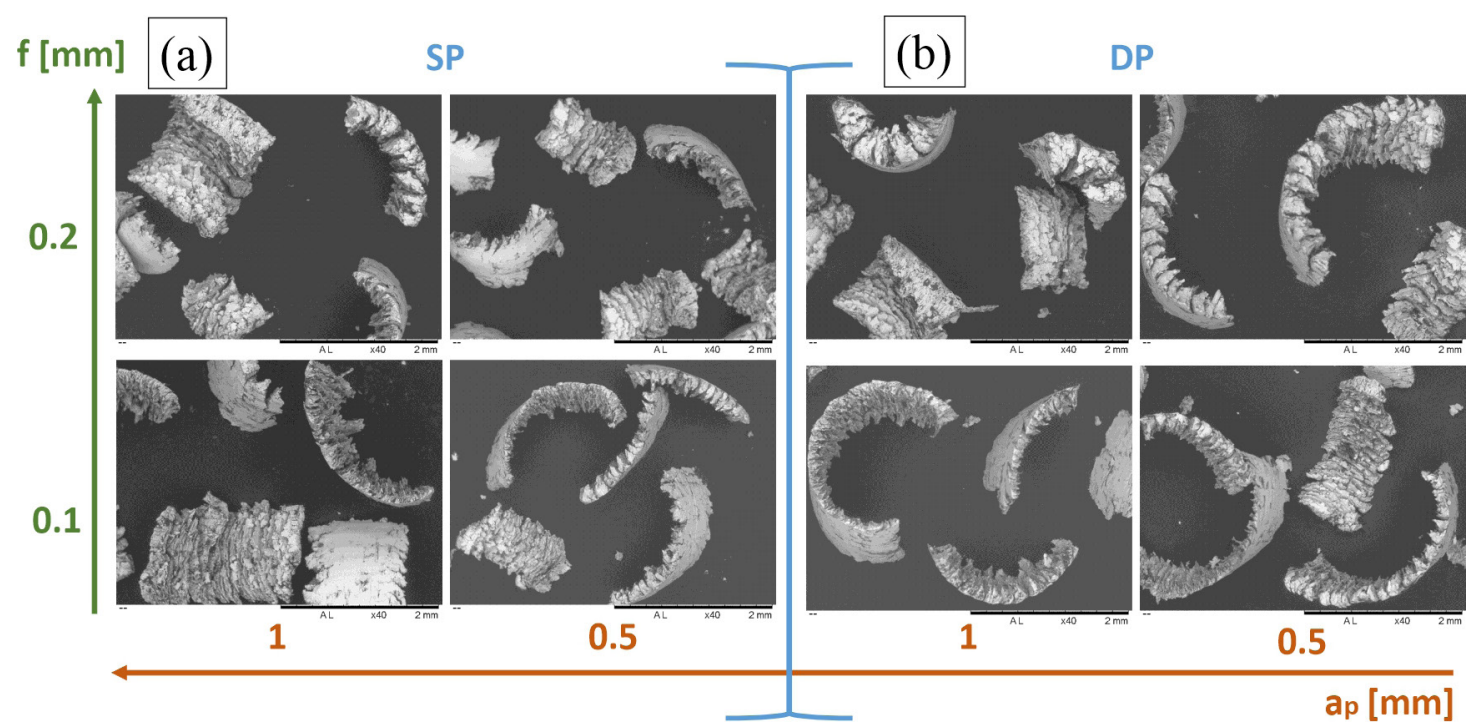

Figure 8. Influence of the feed and depth of cut in the chips shape in the tests performed with $v_{c}=200 \mathrm{~m} / \mathrm{min}$ for the (a) SP and (b) DP material. 


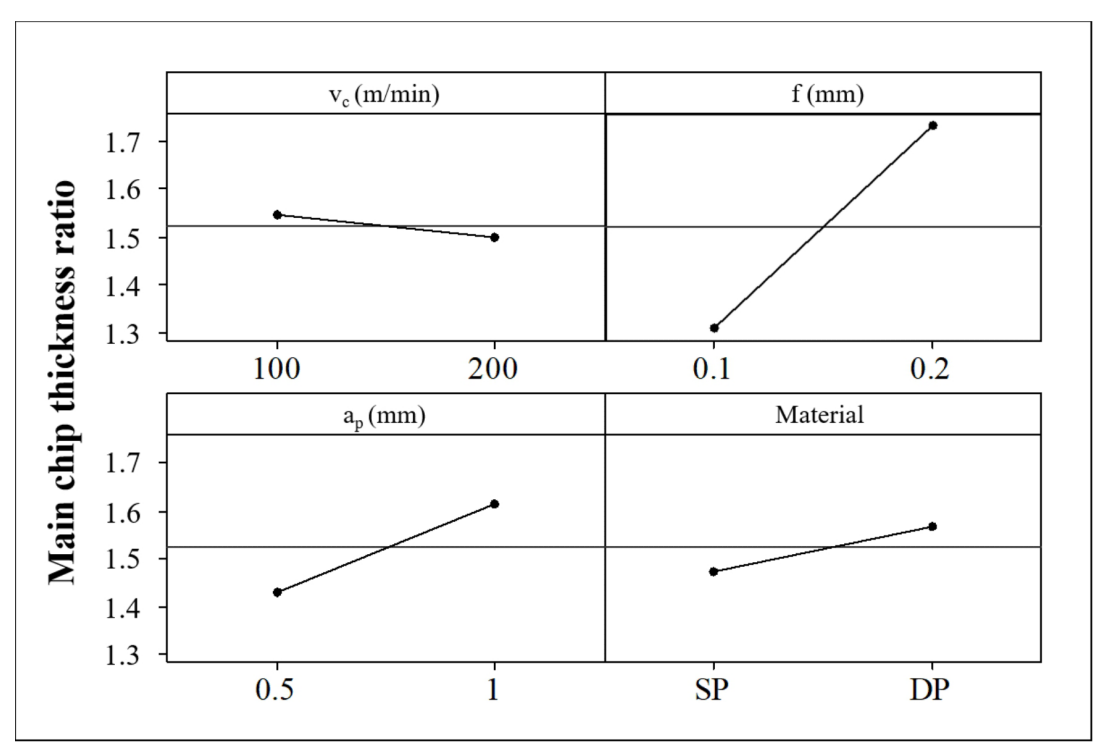

Figure 9. Main effects plot of cutting parameters and manufacturing route on the chip thickness ratio.

showed a reduction in the size of the chip arcs. As the feed rate increases, undeformed chip thickness (h) increases causing the machining force components to increase (Figure 4). The increase in the machining thickness causes greater plastic deformation during cutting, which results in a greater hardening of the machined material, thereby generating shorter chips ${ }^{39,40}$.

The machining of DP materials generated chips with a larger arc size than SP materials (Figure 8). In relation to SP materials, DP materials have a higher density due to reduced porosity ${ }^{5}$. As a result, the greater homogeneity in the microstructure of DP materials (due to the reduction of porosity) provides greater continuity in chip formation, thus resulting in chips with larger arc sizes. The variation in depth of cut from 0.5 to $0.1 \mathrm{~mm}$ (Figure 8) did not have an influence on the shape, regardless of the materials manufacturing route. The tests carried out with $\mathrm{v}_{\mathrm{c}}=100 \mathrm{~m} / \mathrm{min}$ did not show significant differences in the chips shape shown in Figure 8.

Figure 9 presented the graph of average effect of the cutting parameters and the materials manufacturing route on the chip thickness ratio. The variation in the cutting speed from 100 to $200 \mathrm{~m} / \mathrm{min}$ resulted in an approximate reduction of $5 \%$, regardless of the manufacturing route and feed.

The increase of cutting speed results in an increase in temperature in the region of the cut, thereby reducing the forces acting on the process due to the loss of mechanical strength of the material ${ }^{11-14,26}$, according to the results found in the present study (Figure 4). However, the increase in cutting speed also provides a reduction in plastic deformation due to the speed with which the tool cuts the part, thus generating a shorter contact time. The result of this phenomenon is the increase in the speed with which the material passes through the primary shear zone ${ }^{12,13}$.

The variation of the feed from 0.1 to $0.2 \mathrm{~mm}$ provided an increase of around $25 \%$ in the value of the chip thickness ratio (Figure 9). The increase in the depth of cut resulted in an approximate $10 \%$ increase in the chip thickness ratio.
Increasing the feed and depth of cut results in an increase in the undeformed chip thickness (h) and machining width (b), respectively. Thus, a greater amount of material removed occurs, which induces higher rates of plastic deformation ${ }^{12,13,41,42}$.

The manufacturing route SP in comparison with DP resulted in an increase of approximately $10 \%$ in the chip thickness ratio (Figure 9). The double pressing provided materials with an increase in mechanical strength (around $50 \%$ ) higher than SP materials (Figure 2), due to its higher density $^{5}$. Thus, greater forces occur during the machining process (Figure 4), leading to an increase in plastic deformations. Through ANOVA, the variation in cutting speed, feed and depth of cut had a significant influence $(\mathrm{P}$-value $=0.003)$ on the chip thickness ratio. The materials manufacturing route presented a significant influence $(\mathrm{P}$-value $=0.001)$ on the chip thickness ratio.

\section{Conclusion}

Based on the results obtained in the present study, it can be concluded that:

- The increase in cutting speed resulted in a reduction in the machining force components, regardless of the materials manufacturing route. The opposite behavior was verified with the increase of the feed and the depth of cut, which resulted in the increase of the cutting force, feed force and passive force, both for the SP and DP material.

- The materials manufacturing route influenced the machining force components. The increasing mechanical strength of the DP materials in relation to the SP, around $50 \%$, provided an increase of approximately $10 \%$ for the cutting and feed force and around $25 \%$ for the passive force.

- The machining process provided surface roughness with maximum height values $-\mathrm{S}_{\mathrm{z}}$ between 28.3 to $10.8 \mu \mathrm{m}$, Kurtosis $-\mathrm{S}_{\mathrm{ku}}>3$ and Skewness $-\mathrm{S}_{\mathrm{sk}}<0.3$. 
- The cutting speed significantly influenced the maximum height $-\mathrm{S}_{\mathrm{z}}$.

- The machined surfaces in DP materials reduced around $15 \%$ the maximum height $\left(\mathrm{S}_{\mathrm{z}}\right.$ parameter $)$ in relation to SP materials.

- Regardless of the variation in cutting parameters, the materials manufacturing route modified the morphological space of the machined surfaces. DP materials presented surfaces with lower valley distribution ( $\mathrm{S}_{\mathrm{sk}}$ parameter) and higher Kurtosis (Sku parameter) in relation to the machined surfaces in SP materials.

- The variation of the cutting speed modified the morphological space of the machined surfaces. With the cutting speed of $100 \mathrm{~m} / \mathrm{min}$, regardless of the materials manufacturing route, the machined surfaces presented lower valley distribution $\left(\mathrm{S}_{\mathrm{sk}}>-0.2\right)$ associated with lower Kurtosis (parameter $\mathrm{S}_{\mathrm{ku}}<5$ ) when compared to the machined surfaces with cutting speed of $200 \mathrm{~m} / \mathrm{min}$.

- Regardless of the variation in cutting parameters and the materials manufacturing route, the types of chips formed were segmented.

- The chip thickness ratio significant influenced with the variation of the cutting parameters. The increase in cutting speed from 100 to $200 \mathrm{~m} / \mathrm{min}$ resulted in a reduction of around 5\% in the chip thickness ratio. The increase in the feed from 0.1 to $0.2 \mathrm{~mm}$ and the depth of cut from 0.5 to $1 \mathrm{~mm}$ results in an approximate increase of $25 \%$ and $10 \%$, respectively.

- The materials manufacturing route significant influenced on the chip thickness ratio. The DP materials presented an increase of around 10\% in the chip thickness ratio in relation the SP materials.

\section{Acknowledgements}

The authors would like to thank CNPQ, CAPES, and Embraco for funding this research. The authors would also like to thank LABMAT, CERMAT, LMP, and the Program of Post-Graduation in Mechanical Engineering (POSMEC) of the Federal University of Santa Catarina.

\section{References}

1. Binder C, Hammes G, Schroeder RM, Klein AN, De Mello JDB, Binder R, et al. Fined tuned steels point the way to focused future. Met Powder Rep. 2010;65:29-37.

2. Holmberg K, Erdemir A. The impact of tribology on energy use and $\mathrm{CO} 2$ emission globally and in combustion engine and electric cars. Tribol Int. 2019;135:389-96.

3. Holmberg K, Erdemir A. Influence of tribology on global energy consumption, costs and emissions. Friction. 2017;5:263-84.

4. Hammes G, Mucelin KJ, Gonçalves PC, Binder C, Binder R, Janssen R, et al. Effect of hexagonal boron nitride and graphite on mechanical and scuffing resistance of self-lubricating iron based composite. Wear. 2017;376-377:1084-90.

5. Hammes G, Schroeder R, Binder C, Klein AN, De Mello JDB. Effect of double pressing/double sintering on the sliding wear of self-lubricating sintered composites. Tribol Int. 2014;70:119-27.

6. Qin W, Fu L, Zhu J, Yang W, Li DE, Zhou L. Tribological properties of self-lubricating ta-cu films. Appl Surf Sci. 2018;435:1105-13.
7. Binder C, Bendo T, Pereira RV, Hammes G, De Mello JDB, Klein AN. Influence of the sic content and sintering temperature on the microstructural, mechanical and tribological properties of sintered self-lubricating composites. Powder Metall. 2016;59:110.

8. Binder C, Bendo T, Hammes G, Neves GO, Binder R, De Mello JDB, et al. Structure and properties of in situ-generated two-dimensional turbostratic graphite nodules. Carbon. 2017; 124:685-92.

9. Smith GT, Allsop MJ. Some aspects in the surface integrity associated with turning of powder metallurgy compacts. Wear. 1991;151:289-302.

10. Walker JM. Handbook of manufacturing engineering. New York: Marcel Dekker; 1996.

11. Trent EM, Wright PK. Metal cutting. 4th ed. Woburn: ButterworthHeinemann; 2000.

12. König W, Klocke F. Fertigungsverfahren 1. Drehen, Fräsen, Bohren. 5th ed. Berlin: Springer-Verlag GmbH; 1997.

13. Klocke F. Manufacturing processes 1. Berlim: Springer; 2011.

14. Šalak A, Vasiko K, Selecka M, Danninger H. New short time face turning method for testing the machinability of pm steels. J Mater Process Technol. 2006;176:62-9.

15. M'saoubi R, Czotscher T, Andersson O, Meyerb D. Machinability of powder metallurgy steels using PcBN inserts. Procedia CIRP. 2014;14:83-8.

16. Nieslony P, Kiszka P. An investigation of surface texture after turning PM armco iron. Procedia CIRP. 2012;1:671-2.

17. Grzesik W. Prediction of the functional performance of machined components based on surface topography: state of the art. J Mater Eng Perform. 2016;25:4460-8.

18. Hammes G. Aços sinterizados autolubrificantes a seco com elevada resistência mecânica associada a baixo coeficiente de atrito. [thesis]. Florianópolis: Federal University of Santa Catarina; 2011.

19. Klein AN, Cardoso RP, Pavanati HC, Binder C, Maliska AM, Hammes G, et al. DC Plasma technology applied to powder metallurgy: an overview. Plasma Sci Technol. 2013;15:70-81.

20. Machado R, Ristow W, Klein AN, Muzart JLR, Fredel MC, Wendhausen PAP, et al. Industrial plasma reactor for plasma assisted thermal debinding of powder injection-molded parts. U.S. Patent 7718919. 2004 Aug 06.

21. Metal Powder Industries Federation. Standard test methods for metal powders and powder metallurgy products. New Jersey: Metal Powder Industries Federation; 2012. p. 37-42.

22. Ebersbach FG. Efeitos do processo de torneamento nas propriedades de superfície em compósitos autolubrificantes sinterizados. [thesis]. Florianópolis: Federal University of Santa Catarina; 2018.

23. Ebersbach FG, Schroeter RB, Binder C, Klein AN. Análise das componentes da força de usinagem no torneamento de compósitos autolubrificantes sinterizados. In: 10th Congresso Brasileiro de Engenharia de Fabricação; 2019 Aug 05-07; São Carlos, São Paulo, Brazil. p. 1-5.

24. ISO: International Organization for Standardization. Geometrical Product Specifications (GPS) - Filtration - Part 71: Robust Areal Filters: Gaussian Regression Filters (ISO 16610-71). Sweden: ISO; 2014.

25. Montgomery DC, Runger GC. Applied statistics and probability for engineers. 3rd ed. New York: John Wiley and Sons; 2003.

26. Yallese MA, Chaoui K, Zeghib N, Boulanouar L, Rigal JF. Hard machining of hardened bearing steel using cubic boron nitride tool. J Mater Process Technol. 2009;209:1092-104.

27. Rao KSS, Allamraju KV. Effect on microhardness and residual stress in cnc turning of aluminium 7075 alloy. Mater Today. 2017;4:975-81.

28. Shoba CH, Ramanaiah N, Nageswara RD. Effect of reinforcement on the cutting forces while machining metal matrix composites - 
an experimental approach. Engineering Science and Technology, an International Journal. 2015;18:658-63.

29. Pramanik A, Zhang LC, Arsecularatne JA. Prediction of cutting force in machining of metal matrix composites. Int $\mathrm{J}$ Mach Tools Manuf. 2006;46:1795-803.

30. Moravčíková J. Cutting material influence on the quality of the machined surface. Procedia Eng. 2015;100:328-33.

31. Correia E, Davim JP. Surface roughness measurement in turning carbon steel AISI 1045 using wiper inserts. Measurement. 2011;44:1000-5

32. Zhang PRZ, Liu Q, Guo YB. Machinability for dry turning of laser cladded parts with conventional vs. wiper insert. J Manuf Process. 2017;28:494-9.

33. Neugebauer R, Bouzakis KD, Denkena B, Klocke F, Sterzing A, Tekkaya AE, et al. Velocity effects in metal forming and machining processes. CIRP Ann. 2011;60:627-50.

34. Manivel D, Gandhinathan R. Optimization of surface roughness and tool wear in hard turning of austempered ductile iron (grade 3) using taguchi method. Measurament. 2016;93:108-16.

35. Grzesik W, Wanat T. Surface finish generated in hard turning of quenched alloy steel parts using conventional and wiper ceramic inserts. Int J Mach Tools Manuf. 2006;46:1988-95.
36. D'addona DM, Raykar S. Analysis of surface roughness in hard turning using wiper insert geometry. Procedia CIRP. 2016;41:841-6.

37. Ebersbach FG, Carvalho DL, Schroeter RB, Binder C, Klein AN. Effect of turning parameters on the surface of sintered self-lubricating composites. Int J Adv Manuf Technol. 2019;101:3143-56.

38. Komanduri R, Brown RH. On the mechanics of chip segmentation in machining. J Manuf Sci Eng. 1981;103(1):33-51.

39. El-Gallab M, Sklad M. Machining of Al/SiC particle metalmatrix composites: Part I: Tool performance. J Mater Process Technol. 1998;83(1-3):151-8.

40. Joshi SS, Ramakrishnan N, Ramakrishnan P. Analysis of chip breaking during orthogonal machining of $\mathrm{Al} / \mathrm{SiC}$ composite. J Mater Process Technol. 1999;88:90-6.

41. Katuku K, Koursaris A, Sigalas I. Wear, cutting forces and chip characteristics when dry turning ASTM grade 2 austempered ductile iron with PcBN cutting tools under finishing conditions. J Mater Process Technol. 2009;209:2412-20.

42. Mohammed WM, $\mathrm{Ng}$ E, Elbestawi MA. Modeling the effect of the microstructure of compacted graphite iron on chip formation. Int J Mach Tools Manuf. 2011;51(10-11):753-65. 